\title{
PENGEMBANGAN RPP MATEMATIKA SCIENTIFIC
}

\author{
Saminanto \\ Jurusan Tadris Matematika FITK IAIN Walisongo \\ Jl. Prof. Dr. Hamka Ngaliyan Semarang (024) 7601295 \\ Email: anto iain@yahoo.com
}

\begin{abstract}
Abstrak
Kurikulum 2013 merupakan kurikulum yang menggunakan sistem tematik dan mengarahkan pola pikir peserta didik berdasarkan logika. Proses pembelajaran dirancang sedemikian rupa untuk mencapai standar kompetensi, kompetensi dasar serta indikator yang telah ditetapkan. Dibutuhkan pengembangan rencana pelaksanaan pembelajaran (RPP) yang dapat mencapai tujuan tersebut sehingga sesuai dengan target pencapaian kurikulum 2013. Pengembangan ini menghasilkan sebuah rancangan pembelajaran yang disebut RPP scientific.
\end{abstract}

Kata Kunci: Kurikulum 2013, Rencana Pelaksanaan Pembelajaran, Pendekatan Scientific 


\section{PENDAHULUAN}

Karakteristik pembelajaran pada setiap satuan pendidikan terkait erat dengan Standar Kompetensi Lulusan dan Standar Isi. Standar Kompetensi Lulusan memberikan kerangka konseptual tentang sasaran pembelajaran yang harus dicapai. Standar Isi memberikan kerangka konseptual tentang kegiatan belajar dan pembelajaran yang diturunkan dari tingkat kompetensi dan ruang lingkup materi.

Sesuai dengan Standar Kompetensi Lulusan, sasaran pembelajaran mencakup pengembangan ranah sikap, pengetahuan, dan keterampilan yang dielaborasi untuk setiap satuan pendidikan. Ketiga ranah kompetensi tersebut memiliki lintasan perolehan (proses psikologis) yang berbeda. Ranah sikap diperoleh melalui aktivitas "menerima, menjalankan, menghargai, menghayati, dan mengamalkan". Ranah pengetahuan diperoleh melalui aktivitas "mengingat, memahami, menerapkan, menganalisis, mengevaluasi, mencipta", sementara ranah keterampilan diperoleh melalui aktivitas "mengamati, menanya, mencoba, menalar, menyaji, dan mencipta".

Karaktersitik kompetensi beserta perbedaan lintasan perolehannya tersebut turut serta mempengaruhi karakteristik standar proses. Untuk memperkuat pendekatan ilmiah (scientific), tematik terpadu (tematik antarmata pelajaran), dan tematik (dalam suatu mata pelajaran) perlu diterapkan pembelajaran berbasis penyingkapan/penelitian (discovery/inquiry learning). Dan untuk mendorong kemampuan peserta didik dalam menghasilkan karya kontekstual, baik individual maupun kelompok, maka sangat disarankan menggunakan pendekatan pembelajaran yang menghasilkan karya berbasis pemecahan masalah (project based learning).

Rincian gradasi sikap meliputi menerima, menjalankan pengetahuan, menghargai, menghayati dan mengamalkan. Untuk gradasi pengetahuan meliputi mengingat, memahami, menerapkan, menganalisis dan mengevaluasi. Sedangkan gradasi keterampilan meliputi mengamati, menanya, mencoba, menalar, menyaji dan mencipta. 
Karakteristik proses pembelajaran disesuaikan dengan karakteristik kompetensi. Pembelajaran tematik terpadu di SD/MI/SDLB/Paket $\mathrm{A}$ dan disesuaikan dengan tingkat perkembangan peserta didik. Proses pembelajaran di SMP/MTs/SMPLB/Paket B disesuaikan dengan karakteristik kompetensi yang mulai memperkenalkan mata pelajaran dengan mempertahankan tematik terpadu pada IPA dan IPS. Karakteristik proses pembelajaran di SMA/MA/SMALB/SMK/MAK/Paket C/ Paket C Kejuruan secara keseluruhan berbasis mata pelajaran, meskipun pendekatan tematik masih dipertahankan. Sementara proses pada SDLB, SMPLB, dan SMALB diperuntukkan bagi tuna netra, tuna rungu, tuna daksa, dan tuna laras yang intelegensinya normal.

Secara umum pendekatan belajar yang dipilih berbasis pada teori tentang taksonomi tujuan pendidikan yang dalam lima dasawarsa terakhir secara umum sudah dikenal luas. Berdasarkan teori taksonomi tersebut capaian pembelajaran dapat dikelompokkan dalam tiga ranah yakni: ranah kognitif, afektif dan psikomotor. Penerapan teori taksonomi dalam tujuan pendidikan di berbagai negara dilakukan secara adaptif sesuai dengan kebutuhannya masing-masing. Undang-Undang Nomor 20 Tahun 2003 tentang Sistem Pendidikan Nasional telah mengadopsi taksonomi dalam bentuk rumusan sikap, pengetahuan, dan keterampilan.

Proses pembelajaran sepenuhnya diarahkan pada pengembangan ketiga ranah tersebut secara utuh/holistik, artinya pengembangan ranah yang satu tidak bisa dipisahkan dengan ranah lainnya. Dengan demikian proses pembelajaran secara utuh melahirkan kualitas pribadi yang mencerminkan keutuhan penguasaan sikap, pengetahuan, dan keterampilan. 


\section{RENCANA PELAKSANAAN PEMBELAJARAN}

\section{Pengertian}

Rencana Pelaksanaan Pembelajaran (RPP) adalah rencana kegiatan pembelajaran tatap muka untuk satu pertemuan atau lebih. RPP dikembangkan dari silabus untuk mengarahkan kegiatan pembelajaran peserta didik dalam upaya mencapai Kompetensi Dasar (KD). Setiap pendidik pada satuan pendidikan berkewajiban menyusun RPP secara lengkap dan sistematis agar pembelajaran berlangsung secara interaktif, inspiratif, menyenangkan, menantang, efisien, memotivasi peserta didik untuk berpartisipasi aktif, serta memberikan ruang yang cukup bagi prakarsa, kreativitas, dan kemandirian sesuai dengan bakat, minat, dan perkembangan fisik serta psikologis peserta didik. RPP disusun berdasarkan KD atau subtema yang dilaksanakan dalam satu kali pertemuan atau lebih.

\section{Komponen RPP}

Komponen RPP sesuai kurikulum 2013 dengan menjabarkan Permendikbud No. 65 Tahun 2013 dapat dijelaskan sebagai berikut.

1. Identitas sekolah yaitu nama satuan pendidikan

2. Identitas mata pelajaran atau tema/subtema, untuk di SD/MI menggunakan tema kecuali mapel PAI dan Budi Pekerti (sesuai permendikbud No. 67 tahun 2013), sedang SMP/MTs dan SMA/MA menggunakan mata pelajaran;

3. Kelas/semester;

4. Materi pokok, menggunakan kata benda dari KD/indikator yang diambil dalam pembelajaran tersebut.

5. Alokasi waktu ditentukan sesuai dengan keperluan untuk pencapaian KD dan beban belajar dengan mempertimbangkan jumlah jam pelajaran yang tersedia dalam silabus dan KD yang harus dicapai;

6. Tujuan pembelajaran yang dirumuskan berdasarkan KD, dengan menggunakan kata kerja operasional yang dapat diamati dan diukur, yang mencakup sikap, pengetahuan, dan keterampilan. Tujuan pembelajaran mengandung 4 unsur 
yaitu A (audience/peserta didik), B (behaviour/tujuan yang dicapai), C (condition/cara pencapaian) dan D (degree/ukuran capaian baik sikap, pengetahuan dan ketrampilan);

7. Kompetensi dasar dan indikator pencapaian kompetensi;

8. Materi pembelajaran, pengembangan dari materi pokok secara ringkas yang memuat fakta, konsep, prinsip, dan prosedur yang relevan, dan ditulis dalam bentuk butir-butir sesuai dengan rumusan indikator ketercapaian kompetensi;

9. Metode pembelajaran, digunakan oleh pendidik untuk mewujudkan suasana belajar dan proses pembelajaran agar peserta didik mencapai KD yang disesuaikan dengan karakteristik peserta didik dan KD yang akan dicapai;

10. Media pembelajaran, berupa alat bantu proses pembelajaran untuk menyampaikan materi pelajaran;

11. Sumber belajar, dapat berupa buku, media cetak dan elektronik, alam sekitar, atau sumber belajar lain yang relevan;

12. Langkah-langkah pembelajaran dilakukan melalui tahapan pendahuluan, inti, dan penutup; dan penilaian hasil pembelajaran.

\section{Prinsip Penyusunan RPP}

Dalam mengembangkan RPP agar utuh untuk melahirkan kualitas pribadi yang mencerminkan keutuhan penguasaan sikap, pengetahuan, dan keterampilan sesuai dengan fungsi dan tujuan kurikulum 2013, maka harus memperhatikan prinsipprinsip sebagai berikut:

1. Perbedaan individual peserta didik antara lain kemampuan awal, tingkat intelektual, bakat, potensi, minat, motivasi belajar, kemampuan sosial, emosi, gaya belajar, kebutuhan khusus, kecepatan belajar, latar belakang budaya, norma, nilai, dan/atau lingkungan peserta didik.

2. Partisipasi aktif peserta didik.

3. Berpusat pada peserta didik untuk mendorong semangat belajar, motivasi, minat, kreativitas, inisiatif, inspirasi, inovasi dan kemandirian. 
4. Pengembangan budaya membaca dan menulis yang dirancang untuk mengembangkan kegemaran membaca, pemahaman beragam bacaan, dan berekspresi dalam berbagai bentuk tulisan.

5. Pemberian umpan balik dan tindak lanjut RPP memuat rancangan program pemberian umpan balik positif, penguatan, pengayaan, dan remedi.

6. Penekanan pada keterkaitan dan keterpaduan antara KD, materi pembelajaran, kegiatan pembelajaran, indikator pencapaian kompetensi, penilaian, dan sumber belajar dalam satu keutuhan pengalaman belajar.

7. Mengakomodasi pembelajaran tematik-terpadu, keterpaduan lintas mata pelajaran, lintas aspek belajar, dan keragaman budaya.

8. Penerapan teknologi informasi dan komunikasisecara terintegrasi, sistematis, dan efektif sesuai dengan situasi dan kondisi. 


\section{PENGEMBANGAN RPP PAIKEM SCIENTIFIC SESUAI KURIKULUM 2013.}

Untuk mengembangkan RPP sesuai dengan kebutuhan kurikulum 2013, seorang guru harus menguasai model-model pembelajaran PAIKEM (kooperatif, penyingkapan/discovery, penelitian/inquiry learning, menghasilkan karya berbasis pemecahan masalah/project based learning), pendekatan tematik integratif, pendekatan scientific (pendekatan ilmiah), dan nilai-nilai pendidikan karakter yang tertuang dalam standar kelulusan.

Pelaksanaan pembelajaran merupakan implementasi dari RPP. Pelaksanaan pembelajaran PAIKEM Scientific sesuai dengan kurikulum 2013 meliputi kegiatan pendahuluan, kegiatan inti dan kegiatan penutup yang dapat dikembangkan sebagai berikut:

\section{a. Kegiatan Pendahuluan}

Dalam kegiatan pendahuluan, guru:

1) menyiapkan peserta didik secara psikis dan fisik untuk mengikuti proses pembelajaran;

2) memberi motivasi belajar siswa secara kontekstual sesuai manfaat dan aplikasi materi ajar dalam kehidupan sehari-hari, dengan memberikan contoh dan perbandingan lokal, nasional dan internasional;

3) mengajukan pertanyaan-pertanyaan yang mengaitkan pengetahuan sebelumnya dengan materi yang akan dipelajari;

4) menjelaskan tujuan pembelajaran atau kompetensi dasar yang akan dicapai; dan

5) menyampaikan cakupan materi dan penjelasan uraian kegiatan sesuai silabus.

\section{b. Kegiatan Inti}

Kegiatan inti menggunakan model pembelajaran PAIKEM (kooperatif, penyingkapan/discovery, penelitian/inquiry learning, menghasilkan karya berbasis pemecahan masalah/project based learning), pendekatan tematik integratif, pendekatan scientific (pendekatan ilmiah), dan integrasi nilai-nilai 
pendidikan karakter yang tertuang dalam standar kelulusan, media pembelajaran, dan sumber belajar yang disesuaikan dengan karakteristik peserta didik dan mata pelajaran. Semua itu dalakukan untuk melahirkan kualitas pribadi yang mencerminkan keutuhan penguasaan sikap, pengetahuan, dan keterampilan.

Jadi dalam kegiatan inti pelaksaan pembelajaran harus menggunakan langkah besar dengan pendekatan scientific yaitu:

1) Mengamati dapat dilakukan dengan kegiatan mengamati gambar, melihat contoh, membaca kembali, mengamati lingkungan, mengamati tayangan

2) Menanya dapat dilakukan dengan kegiatan tanya jawab, berdiskusi, membuat soal/pertanyaan

3) Menalar dapat dilakukan dengan kegiatan mengeidentifikasi, membuat daftar, membandingkan, membedakan, menyampaikan pendapat, berargumentasi

4) Mencoba dapat dilakukan dengan kegiatan mempraktekan, mencoba, eksperimen

5) Mengkomunikasikan/membuat jejaring dapat dilakukan dengan kegiatan peduli sosial,peduli lingkungan, berkelompok, kerjasama.

Bisa juga kegiatan pendekatan scientific/ilmiah dijabarkan dan dilakukan secara lebih terperinci lagi yaitu mengamati, menanya, mencoba, mengolah, menyaji, menalar dan mencipta. Yang menjadi catatan penting dalam setiap kegiatan pembelajaran, belum tentu bisa menerapkan semua langkah kegiatan pendekatan scientific. Tetapi prinsipnya jangan meninggalkan kegiatan pembelajaran melalui pendekatan scientific.

\section{c. Kegiatan Penutup}

Dalam kegiatan penutup, guru bersama siswa baik secara individual maupun kelompok melakukan refleksi untuk mengevaluasi: 
1) seluruh rangkaian aktivitas pembelajaran dan hasil-hasil yang diperoleh untuk selanjutnya secara bersama menemukan manfaat langsung maupun tidak langsung dari hasil pembelajaran yang telah berlangsung;

2) memberikan umpan balik terhadap proses dan hasil pembelajaran;

3) melakukan kegiatan tindak lanjut dalam bentuk pemberian tugas, baik tugas individual maupun kelompok; dan

4) menginformasikan rencana kegiatan pembelajaran untuk pertemuan berikutnya. 
CONTOH RPP PAIKEM SCIENTIFIC TEMATIK

\section{RENCANA PELAKSANAAN PEMBELAJARAN (RPP)}

$\begin{array}{ll}\text { Satuan Pendidikan } & \text { : MTs Surga } \\ \text { Mata Pelajaran } & \text { : Matematika } \\ \text { Kelas/Semester } & \text { : VIII / } 2\end{array}$

A. Materi Pokok

Nilai $\pi$ dan keliling lingkaran

B. Alokasi Waktu

$2 \times 40$ menit

C. KI dan KD

Kompetensi Inti:

3. Memahami dan menerapkan pengetahuan (faktual, konseptual, prosedural) berdasarkan rasa ingin tahunya tentang ilmu pengetahuan, teknologi, seni, terkait fenomena dan kejadian tampak mata

\section{Kompetensi Dasar :}

3.6. Memahami unsur, keliling, dan luas dari lingkaran

D. Indikator

1.6.1. Menemukan nilai $\pi$

1.6.2. Menemukan rumus keliling lingkaran

E. Tujuan Pembelajaran

Dengan melakukan diskusi kelompok, demonstrasi dan inquiry peserta didik dapat:

1. menemukan nilai $\pi$ dengan benar

2. menemukan rumus keliling lingkaran dengan benar

\section{F. Materi Pembelajaran}
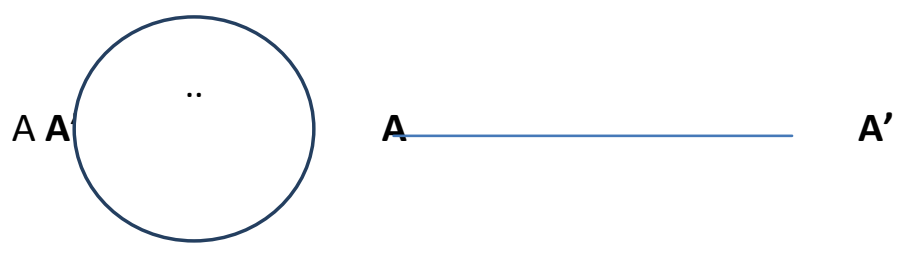

Keliling lingkaran pada gambar di atas (1) menunjukkan sebuah lingkaran dengan titik A terletak disebarang lengkungan lingkaran. Jika lingkaran tersebut 
dipotong di titik $A$, kemudian direbahkan, hasilnya adalah sebuah garis lurus $A^{\prime}$ seperti pada gambar (2). Panjang garis lurus tersebut merupakan keliling lingkaran. Jadi, keliling lingkaran adalah panjang lengkungan pembentuk lingkaran tersebut.

Cara di atas, keliling sebuah lingkaran dapat juga ditentukan menggunakan rumus. Akan tetapi, rumus ini bergabung pada sebuah nilai, yaitu $\pi$ (dibaca phi). Menurut penelitian yang cermat ternyata nilai $\pi=3,14159265358979324836$... Jadi, nilai hanyalah suatu pendekatan. Jika dalam suatu perhitungan hanya memerlukan ketelitian sampai dua tempat desimal. Jadi, pendekatan untuk $\pi$ :

$$
\pi=3,14 \text { atau } \frac{22}{7} \text {. }
$$

Lingkaran, nilai perbandingan $\frac{\text { keliting }(K)}{\text { diameter }(d)}$ menunjukkan bilangan yang sama atau tetap disebut $\pi$. Karena $\frac{K}{d}=\pi$, sehingga didapat $\mathrm{K}=\pi \cdot d$ Karena panjang diameter adalah $2 \times$ jari-jari atau $d=2 r$, maka $K=2 \pi$ r. Jadi, didapat rumus keliling $(K)$ lingkaran dengan diameter $(d)$ atau jari-jari $(r)$ adalah :

$$
\mathrm{K}=\pi d \text { atau } \mathrm{K}=2 \pi r
$$

\section{G. Pendekatan dan metode pembelajaran}

Pendekatan : scientific/ilmiah

Metode $\quad$ :Small group discution, demonstrasi, Inkuiri, galery walk.

\section{H. Media Pembelajaran}

Kertas karton, kertas plano, media lingkaran, penggaris, benang dan lembar kerja.

\section{Sumber Belajar}

Buku paket BSE MTK kelas VIII SMP

\begin{tabular}{|c|c|c|c|}
\hline \multirow[b]{2}{*}{ No } & \multirow[b]{2}{*}{ Kegiatan Pembelajaran } & \multicolumn{2}{|c|}{ Pengorganisasian } \\
\hline & & $\begin{array}{c}\text { Peserta } \\
\text { didik }\end{array}$ & Waktu \\
\hline & Kegiatan Awal & & \\
\hline 1 & $\begin{array}{l}\text { Guru memasuki kelas tepat waktu, kemudian guru } \\
\text { mengucap salam dan menyuruh peserta didik untuk berdoa } \\
\text { terlebih dahulu. Sebelum memulai pelajaran, guru dan } \\
\text { peserta didik mengucapkan basmallah bersama-sama. } \\
\text { (sikap disiplin dan religius) }\end{array}$ & K & 5 menit \\
\hline 2 & $\begin{array}{l}\text { Apersepsi: } \\
\text { Menanyakan materi yang sebelumnya yaitu tentang } \\
\text { pengertian lingkaran dan unsur-unsurnya. }\end{array}$ & K & \\
\hline 3 & Motivasi : & $\mathrm{K}$ & \\
\hline
\end{tabular}

J. Langkah-langkah Pembelajaran 


\begin{tabular}{|c|c|c|c|}
\hline & $\begin{array}{l}\text { guru memberikan motivasi yang berhubungan dengan } \\
\text { keliling lingkaran, bahwa banyak sekali benda di alam } \\
\text { semesta berputar/berkeliling, misalnya permainan } \\
\text { drumolen yang terdapat di pasar malam yang gerakannya } \\
\text { seimbang dan perputaran bumi pada porosnya dari arah } \\
\text { barat ke timur selama } 24 \text { jam yang mengakibatkan } \\
\text { terjadinya siang dan malam. Juga bisa menanyakan benda- } \\
\text { benda yang berbentuk lingkaran yang ada di sekitar kita, } \\
\text { baik di lingkungan kelas maupun di rumah. }\end{array}$ & & \\
\hline 4 & $\begin{array}{l}\text { Guru menyampaikan tujuan pembelajaran yaitu: agar } \\
\text { peserta didik mampu menentukan nilai pendekatan } \pi \text {, } \\
\text { rumus keliling lingkaran dan menghitung kelilingnya dengan } \\
\text { benar dan cermat. }\end{array}$ & K & \\
\hline & Kegiatan inti & & \\
\hline 5 & $\begin{array}{l}\text { Mengamati: } \\
\text { Guru meminta peserta didik untuk mengamati benda-benda } \\
\text { yang berbentuk lingkaran yang ada di lingkungan sekolah } \\
\text { untuk dibawa ke dalam kelas. Termasuk diminta untuk } \\
\text { menunjukan benda-benda lingkaran yang dibawanya dari } \\
\text { rumah. }\end{array}$ & K & $\begin{array}{c}10 \\
\text { menit }\end{array}$ \\
\hline 6 & $\begin{array}{l}\text { Menanya: } \\
\text { Guru melakukan tanya jawab untuk menggali unsur-unsur } \\
\text { lingkaran pada benda yang didapatnya. Terutama harus bisa } \\
\text { menemukan diameter dan keliling lingkaran pada benda } \\
\text { masing-masing. }\end{array}$ & K & 5 menit \\
\hline 7 & $\begin{array}{l}\text { Eksperimen dan menalar: } \\
\text { a. Membentuk kelompok dengan peserta } 5 \text { orang. (sikap } \\
\text { kebersamaan) } \\
\text { b. Dengan diskusi dan kerja kelompok diminta untuk } \\
\text { menjiplak benda- benda lingkaran di kertas karton. } \\
\text { Minimal tiap kelompok menjiplak } 5 \text { lingkaran yang } \\
\text { berbeda besarnya. } \\
\text { c. Lingkaran diukur satu per satu, diameternya dengan } \\
\text { menggunakan penggaris dan kelilingnya dengan } \\
\text { menggunakan benang } \\
\text { d. Dari hasil pengukuran diminta untuk menungka dalam } \\
\text { tabel pada kertas plano. }\end{array}$ & 1 & $\begin{array}{c}25 \\
\text { menit }\end{array}$ \\
\hline 8 & $\begin{array}{l}\text { Komunikasi dan menalar: } \\
\text { a. Dari tabel yang dibuat diminta untuk menentukan } \\
\text { b. Nilai } \frac{\text { keliling }}{\text { diameter }} \text { dari tiap lingkaran } \\
\text { c. Mendiskusikan tentang nilai yang didapat apakah hasilnya } \\
\text { mendekati angka yang sama? Itulah yang disebut bilangan }\end{array}$ & K & $\begin{array}{c}25 \\
\text { menit }\end{array}$ \\
\hline
\end{tabular}




\begin{tabular}{|c|c|c|c|}
\hline & $\begin{array}{l}\text { tetap/ } \pi \\
\text { d. Setelah menemukan nilai } \pi \text {, peserta didik diminta untuk } \\
\text { menemukan rumus keliling lingkaran } \\
\text { e. Hasil diskusi tiap kelompok ditulis di plano dipajang di } \\
\text { dinding dekat kelompok masing-masing. } \\
\text { f. Tiap kelompok diminta secara bergiliran melihat hasil } \\
\text { pekerjaan kelompok lain, mengamati dan mencatat yang } \\
\text { perlu } \\
\text { g. Tiap kelompok mempresentasikan dan ditanggapi } \\
\text { kelompok lain } \\
\text { h. Memberikan soal untuk mencari keliling lingkaran }\end{array}$ & & \\
\hline & Penutup & & \\
\hline 9 & $\begin{array}{l}\text { Melakukan refleksi dengan mengajukan pertanyaan atau } \\
\text { tanggapan peserta didik dari kegiatan yang telah } \\
\text { dilaksanakan menyimpulkan keliling lingkaran. Selain itu } \\
\text { juga mengidentifikasi manfaat dari pembelajaran ini }\end{array}$ & K & \multirow{3}{*}{$\begin{array}{c}10 \\
\text { menit }\end{array}$} \\
\hline 10 & $\begin{array}{l}\text { Merencanakan kegiatan tindak lanjut dengan meminta } \\
\text { peserta didik untuk mengerjakan soal terkait keliling } \\
\text { lingkaran }\end{array}$ & K & \\
\hline 11 & $\begin{array}{l}\text { Menyampaikan rencana pembelajaran pada pertemuan } \\
\text { berikutnya. } \\
\text { Guru dan peserta didik mengucapkan hamdallah. } \\
\text { Kemudian Guru mengucap salam dan meninggalkan kelas } \\
\text { tepat waktu. (sikap disiplin dan religius) }\end{array}$ & K & \\
\hline & Jumlah & & $\begin{array}{c}80 \\
\text { menit }\end{array}$ \\
\hline
\end{tabular}

Keterangan: I = Individual; $\mathrm{P}=$ berpasangan; $\mathrm{G}$ = group; $\mathrm{K}=$ klasikal.

\section{K. Penilaian}

Penilaian penugasan kerja kelompok.

1. Instrumen Penilaian:

a. Jumlah benda lingkaran yang ditemukan dan dibawa dari rumah (skor mak 5)

b. Keaktifan dalam berdiskusi (skor mak 5)

c. Ketepatan menentukan diameter dan keliling 5 lingkaran (tiap lingkaran benar skor 1 , salah skor 0 )

d. Menentukan nilai $\pi$ dari 5 lingkaran (tiap lingkaran benar skor 1 , salah skor 0 )

e. Menentukan rumus keliling (benar skor 5 dan salah skor 0 )

$$
\text { Nilai }=\text { jumlah skor } \times 4
$$

\section{Tindak Lanjut:}

Menyelesaikan soal yang terkait denga keliling lingkaran. 
Semarang, 30 Agustus 2013 Guru Kelas

Samin

NIP. 081326721713

Anto

NIP. 02476638126 


\section{DAFTAR PUSTAKA}

Agus Suprijono. 2010. Cooperatif Learning: Teori dan Aplikasi PAIKEM. Yogyakarta: Pustaka Belajar. 2010

Amin Suyitno. 2010. CTL dan Model Pembelajaran Inovatif serta Penerapannya pada SD/SMP Cl-BI. Semarang. Bahan Ajar ini digunakan untuk keperluan pelatihan guru-guru Matematika SD/SMP CI-BI di Salatiga Provinsi Jawa Tengah. 25 Februari 2010.

Amirul Hadi dan Haryanto. 2000. Metodologi Penelitian Pendidikan. Bandung: PustakaSetia

Anas Sudijono. 2009. Pengantar Evaluasi Pendidikan. Jakarta: Rajawali Press

Baharudin. 2010. Teori Belajar Dan Pembelajaran. Jogjakarta. Ar - Ruzz Media.

Depdiknas. 2005. Kamus Besar Bahasa Indonesia. Jakarta: Balai Pustaka. 2003. UU RI No. 20 Tahun 2003. Jakarta: Depdiknas.

Dwi Yulianti. 1984. Bermain Sambil Belajar Sains. Jakarta: PT Indeks. 2010 Engkoswara. Metodologi Pengajaran. Jakarta. Bina Aksara.

Muhaimin. 2001. Paradigma Pendidikan Islam. Upaya Mengefektifkan Pendidikan Agama Islam Di Sekolah. Bandung: Remaja Rosda Karya.

Moh Amin. 1988. Buku Pedoman Laboratorium dan Petunjuk Praktikum Pendidikan IPA Umum. Jakarta. Departemen Pendidikan Dan Kebudayaan.

Mulyasa. 2007. Manajemen Berbasis Sekolah Konsep. Strategi. Dan Implementasi. Bandung. PT Remaja Rosdakarya.

Nana Djumhana. 2009. Pembelajaran Ilmu Pengetahuan Alam. Jakarta: Direktorat Jenderal Pendidikan Islam Departemen Agama RI.

Nana Rukmana. 2006. Model Manajemen Pendidikan Berbasis Kemitraan. Jakarta: ALFABETA.

Nana Sudjana. 1995. Dasar-Dasar Proses Belajar Mengajar. Bandung: Sinar Baru Algesindo.

Nana Sudjana. 2005. Media Pengajaran. Bandung: Sinar Baru.

Riduwan. 2008. Dasar-Dasar Statistika. Bandung: Alfabeta.

Rita Maryana. 2010. Pengelolaan lingkungan belajar. Jakarta: Kencana Prenada Media Group.

S. Rositawaty. 2008. Senang belajar Ilmu Pengetahuan Alam 4: Jakarta: Pusat Perbukuan. Departemen Pendidikan Nasional.

Sudiyono. 2009. Ilmu Pendidikan Islam. Jilid 1. Jakarta : PT. Asdi Mahasatya. 
Sudjana. 2005. Metode Statistika. Bandung: Tarsito.

Sugiyono. 2008. Metode Penelitian Pendidikan (Pendekatan Kuantitatif. Kualitatif. R\&D). Bandung: Alfabeta.

Suharsimi Arikunto. 2006. Prosedur Penelitian Suatu Pendekatan Praktek. Jakarta: Rineka Cipta.

Slameto. 2003. Belajar dan Faktor-faktor yang Mempengaruhinya. Jakarta: Rineka Cipta.

Syaiful Sagala. 2003. Konsep dan Makna Pembelajaran. Bandung: Alfabeta.

Udin S. Winataputra. 2001. Strategi Belajar Mengajar IPA. Jakarta: Universitas Terbuka.

Trianto. 2010. Mendesain Model Pembelajaran Inovatif - Progresif: Konsep dan Implementasinya pada Kurikulum Tingkat Satuan Pendidikan (KTSP). Jakarta: Kencana.

Trianto. 2007. Model Pembelajaran Terpadu Dalam Teori Dan Praktek. Jakarta:Prestasi Pustaka.

Wina Sanjaya. 2007. Stategi Pembelajaran. Jakarta: Kencana. 